\title{
NOTAS
}

\section{Guía para el Lector de Rayuela}

$\mathrm{W}^{\mathrm{L}}$ comentarista incógnito del Times Literary Supplement del 30 de D septiembre de 1965 (London, año $64, \mathrm{n}^{\circ} 3,3 \mathrm{I} 8$, p. 867) dice de Rayzalala de Julio Cortázar (Buenos Aires, Editorial Sudamericana, I963 y 1965), "this is the first great novel of Spanish America". La afirmación del crítico desconccido cierra un ponderado estudio en el que se analizan las obras de varios escritores contemporáneos de la América española. Rayzulla, sin embargo, no ha recibido su merecida recepción entusiasta. Los libros de Cortázar no parecen ser grandes éxitos de crítica, quizá por ser demasiado avanzados para el gusto estético de las mayorías. No ha tenido más suerte en traducciones porque Los premíos apareció en inglés un poco después del Ship of Fools de la muy venerada Katherine Anne Porter. Confrontados con un tratamiento más simbólico y más moderno del mismo tema, los críticos norteamericanos decidieron ignorar el libro argentino. Después de todo, Sbip of Fools estaba ya en manos de Hollywood con toda su maquinaria propagandista en plena marcha.

Rayuela no es una novela fácil. Las instrucciones del autor requieren que se lea jugando a la rayuela, es decir de salto en salto, con omisiones, añadiduras y treguas, todo lo cual requiere paciencia, una buena memoria y un buen conocimiento de autores contemporáneos. El resultado sicológico del salto de páginas y los vaivenes de la acción tienen por objeto sumergir al lector en el mundo desconcertado en que se desarrolla la novela, apresando tanto al personaje como a sus intérpretes. Se presencian las decisiones, dudas y renuncias de un hombre un poco atolondrado, pero muy perspicaz, que va recordando su pasado en cuadros imprecisos. Se con- 
templan los episodios en el momento mismo de desarrollarse y sus recuerdos redivivos dos veces, por el protagonista y por el autor, en diferentes facetas. $Y^{\prime}$ se deja al lector en completa libertad de interpretar el relato mientras va y viene a través de los senderos que Cortázar le señala. El resultado es que el lector tiene que meterse dentro de la novela, tanto estructuralmente como subjetivamente. La misma técnica ha seguido Marta Minujin, que recibió en Buenos Aires el premio Tella en 1964: en El batacazo ha creado un cuadro-escultura que no es solamente para ser visto sino para ser compartido. En El batacazo es necesario entrar, subir, resbalar y sufrir, para entender el propósito del artista y su genio plástico. Tanto Rayuela como El batacazo corresponden a una nueva línea artística que exige del espectador algo más que un homenaje visual.

La novela está aparentemente dividida en dos partes. La primera "es muchos libros, pero sobre todo es dos libros", como dice el autor refiriéndose al libro total. Este libro completo tiene dos aspectos, uno que se lee hasta el capítulo 56, donde termina con tres elegantes estrellas como cualquier libro común y corriente. Otro libro que se lee alternando capítulos, según las instrucciones debidamente provistas por el autor y el tipógrafo, y que se supone es todo el libro tal como el autor quiere que se lea. Todo sucede al mismo tiempo, pero no bajo el tratamiento tradicional de Durrell en el Cuarteto de Alejandría o en el Quijole de la primera parte. Pero Cortázar tiene que profundizar más porque no está describiendo aventuras sino el extraordinario paisaje interior de un hombre que lucha contra su propia destrucción espiritual a través de la memoria y el sueño. Un hombre que siente los peligros de su frialdad introspectiva pero que no puede renunciar ni al análisis ni a la duda. Un hombre sin más fuerza ni recurso que su propio yo negativo, envuelto en palabras y citas, y que incapacitado por el miedo para el amor y el sacrificio, está también incapacitado para vivir y para crear.

En lo que llama Cortázar el primer libro vemos a este hombre en dos facetas de su vida, la primera en París, la segunda de regreso en la Argentina. El segundo libro es a manera de ampliación, con capítulos explicativos, recuerdos detrás de los recuerdos, las lecturas y preferencias literarias del protagonista y del autor, y este autor en persona, vivo y entrometido, disfrazado de personaje al que hay que visitar en un hospital y en su propia casa. En los dos libros abundan las citas, pero más en el segundo, y van desde Paz y Ferlinghetti en las Américas hasta el británico Malcolm Lowry. La teoría e intención de Morelli-Cortázar es "hacer dell 
lector un cómplice, un camarada de camino". La primera impresión es de una novela sin argumento, una pesadilla irracional en que el viejo grito clásico de la vidéa es sueño se ha convertido en el sueño es la vida. No solamente deja de existir la realidad, sino que también se borran los límites del tiempo. Inevitablemente se piensa en Michel Butor y en Alain Robbe-Grillet. Pero también en Cervantes, que tuvo el imprudente descaro de visitar una imprenta catalana haciéndose pasar por Don Quijote. Porque todo el francesismo aparente de la novela sigue la inescapable tradición del realismo práctico de las letras españolas, y corresponde a una línea exacta en que el protagonista lucha por apartarse de la realidad pero ésta lo envuelve con sus fríos brazos vengativos. Envuelve también al autor, que cuando discute la realidad añade de sí mismo: "Morelli no cree en los sistemas onomatopéyicos ni en los letrismos. No se trata de sustituir la sintaxis por la escritura automática o cualquier otro truco al uso. Lo que él quiere es transgredir el hecho literario total, el libro, si querés". Aquí el autor está glosado por el protagonista, pero el resuiltado es que a pesar de las explicaciones y esclarecimientos y a pesar de las instrucciones específicas, la novela tiene una estructura discernible y se puede leer en un lineamiento tradicional. La primera parte es la novelanovela. Los capítulos "prescindibles" abrazan el diario de la novela que emerge, la lucha del autor con sus personajes, el desaliento de todos, inclusive del lector. Esta segunda parte contiene autodefensas, explicaciones, divertimientos, notas autobiográficas, fuentes y dudas. Es la novela de los iniciados tal como la otra es la novela para el lector sin pretensiones y sin curiosidad. Sólo que este lector tímido y holgazán es una víctima propiciatoria para Cortázar, ya que la primera novela no termina, como él afirma, en el capítulo 56. Hay que leer mucho más, porque para que la historia sea completa hay que incluir los capitulos finales en sucesión estrecha: I35-63-88-72-77-I3I-58-13I-58-13I, seguir esta repetición 58I3 I y cerrar con el capítulo 73 , que no es como el autor afirma el primer capítulo sino el último. Estos últimos siete capítulos son parte principal de la novela intrínseca; en ellos el antihéroe confunde realidad y recuerdo y se desmiente el cierre prometedor y optimista del capitulo 56. También es indispensable la repetición de los dos últimos capítulos, 58 y r3I, que con su martilleo monótono descubren que el protagonista está envuelto en un mundo alucinado.

La trama de esta novela-novela dentro de la novela es aparentemente simple. Un expatriado argentino en París, sin oficio ni beneficio, se enamora, a su manera de don Juan hispanoamericano, de otra expatriada un tanto ingenua, un tanto irresponsable. Las conversaciones son arbitraria- 
mente zigzagueantes, algunos episodios son patentes flasbbacks, se siente el aire y el sabor de largas sesiones de sicoanálisis. Las conversaciones y monólogos se convierten en asambleas de autoexoneración. En esta parte el capítulo maestro —uno de los mejores de toda nuestra novelísticaes la muerte del hijo de la querida, en medio de una reunión de intelectuales, cobardes frente a la catástrofe definitiva. La verdad se oculta entre "cañaverales de palabras". De tal manera se acentúa la labia desmedida de los hispanoamericanos y de la bohemia artística que se adivina la ironía cortante, aunque involuntaria, en la larga transcripción de conversaciones brillantes y fofas como fuegos fatuos.

El protagonista - que es en el fondo un meteco- cree sentirse a gusto en París. Solamente un gesto lo delata, el constante subirse del cuello de la "canadiense", el refugiar las manos en los bolsillos, la subterránea protesta de hallarse en un clima extraño entre gentes desconocidas. Este individuo, que se pasa la vida "enhebrando palabras" como él mismo dice, deja cobardemente a su querida cuando ella más lo necesita. Buscándola se enreda en una escena repugnante con una vagabunda andrajosa, en casi una parodia deliberada de lo más escogido de Genet con Genet mismo encerrado en ell coche de la policía que se los lleva a todos. Como resultado tiene que salir de París y regresar a Buenos Aires. Aquí, en el capítulo 37, empieza la segunda parte de la novela, que se mueve en un mundo más tangible. Antes eran los viejos blues transportados, ahora es el tango autóctono. La nueva querida es una Penélope nórdica que ha esperado pacientemente. Al muelle han ido a recibitlo Traveler -el brazo del destino- y su mujer Talita, que lleva un gato amaestrado en una cesta. Irremisiblemente el personaje se enamora de la mujer de Traveler y éste lo nota, una especie de contraparte al Curioso impertinante. El fin, all revés que en Cervantes, sacrifica solamente a un amigo, no porque vivamos en tiempos más libres sino porque no hay adulterio. Traveler consigue para el héroe un trabajo en un circo y después se lo lleva fatalmente a un manicomio cuando él mismo cambia de trabajo. Y es aquí donde la locura callada del protagonista se descarga en delirio de persecución, en el que Traveler sería el victimario. Este "primer" libro termina aparentemente, según consejo del autor, cuando el protagonista en el capítulo 56 se detiene al borde del suicidio.

Como Cortázar está jugando al escondite con sus lectores o exigiendo de ellos un esfuerzo personal para hallar la verdad, el que haya empezado el primer libro con toda inocencia, franqueando los números al pie de cada capítulo, se encuentra que el 55 no conduce a ninguna parte. Aquí se acaban las instrucciones y se pierde el placer de desobedecer al autor, 
pero se queda en cambio el protagonista camino de una felicidad. increíble, capaz de debilidades humanas, apto para la comprensión. Pero después de una ligera duda los osados pueden seguir al capítulo 56 en que el protagonista ha descubierto los bordes de la locura, los ejes del suicidio, simplemente por negarse a pagar el precio del sufrimiento y renuncia que la vida requiere. Para él la existencia es una rayuela donde sus amigos se mueven mecánicamente mientras él los contempla y cree con soberbia que tiene el poder milagroso de manejarlos como títeres.

Pero todo es una broma para despistar a los arrogantes y descorazonar a los humildes que todavía creen en la leche de la bondad humana. Podemos asistir a la desintegración total del héroe, a las escenas de la cura de emergencia y a sus alucinaciones. Y luego de percibir directamente su locura en la repetición de los dos últimos capítulos, cerrar con el 73 , en el que nuestro hombre descubre que nadie lo curará del fuego que le roe el alma, ni siquiera los símbolos. En resumen, para no ser víctima del juego sabio de Cortázar hay que leer su novela como si fuera un libro convencional, desde el i al 56, terminando en la secuencia señalada por el autor y rematar con el capítulo 73. En cambio, para ser partícipe y cómplice en la perdición total del protagonista, para recrear la novela, es necesario seguir al pie de la letra las instrucciones de su autor, que es en definitiva quien tiene que decir la última palabra. Pero. Cortázar no siempre ha seguido las reglas del juego y ha arreglado los capítulos a su gusto y travesura. De seguir fielmente sus instrucciones nos quedamos sin leer el capítulo 55, duplicado por el I33, en donde está la clave de la estructuración cortaziana. El 55, convencional dentro de la novela convencional, nos presenta a Traveler en la noche decisiva emborrachándose mientras espera a su mujer, que cuando llega despliega "diversas teorias". En el capítulo 133 el episodio está detalladamente elaborado, las lecturas, los pensamientos, la borrachera y las teorías desmenuzados y expuestos. $\mathrm{Y}$ si es necesario aceptar que hay que leer el libro tal como su autor y verdadero legítimo dueño quiere que se lea, también es preciso reconocer que para ser usado en una clase, para que un grupo de estudiantes jóvenes y simples entiendan, aunque sea a medias, las tonalidades del libro de Cortázar, es preciso llevarlos paso a paso por la novela convencional antes de sumergirlos en el terremoto de sus ramificaciones. Con este propósito una guía para leer a Cortázar, más que útil, es necesaria.

El libro es demasiado difícil para los suscriptores de la Novela Rosa y demasiado críptico para los que no están insertos en el lenguaje literario. Hay referencias significativas sólo para los iniciados, "no solamente a las Albertinas" o "caer en lo más profundo de la estupidez para acertar con 
el picaporte de la letrina", Proust y Joyce sin cartilla que deletree sus nombres. Lo mismo pasa con Neruda - pero Neruda nos es más fácilcuando se habla de la alegría del ajo. En cambio la novela se burla abiertamente de Julián Marías y de algún que otro escritor sentimental de habla española. La rayuela, por su parte, puede interpretarse como la prisión en que vive el personaje central $-\mathrm{y}$ sus amigos-, sus pasiones, su tradición, su argentinismo, aunque para el personaje mismo la rayuela es la cárcel en que viven los otros. El seudohéroe vive preso en su propio juego, saltando de cuadro en cuadro, sin más refugio que su canadiense, es decir, su propia piel. Casi podría afirmarse que la tesis de Cortázar es que la palabra sin acción, la palabra sin voluntad y sin ética, la palabra sin ternura, es la nada, romanticismo de sicópatas, la bancarrota de la retórica del hedonismo. La angustia egoísta y la estructura de la novela confrontan la pesadilla y el despertar, las relacionss entre la filatería y el arte hasta confundirse en una fábula moral. El hombre que no puede ni crear ni sentir ha perdido su derecho a la vida.

La novela de Cortázar tiene que ser reescrita cada vez que es leída. Siguiendo los elementos que gobiernan un "happening", metiendo las manos hasta el fondo de los sucesos mismos y marcando sus aristas, ha dejado atrás a todas las novelísticas hispanoamericanas del presente, incluso a las más ambiciosas. La artesanía superior de Cortázar se evidencia también en la aplicación estilística del lenguaje. Con simulado descuido se usan los clisés de la clase media hispanoamericana, los que se entienden lo mismo en México que en el Perú, sin estridencias de lunfardo o aztequismos de tribu, a diferencia de la gran mayoría de nuestros escritores que aún no han descubierto que el avión y la radio han reducido la gran frontera americana. El resultado es cosmopolita. Las referencias y las citas - como también la música- no son solamente europeas, son también americanas y comprenden lo mismo una alusión a González Martínez que versos de Rubén Darío. El vocabulario común, los dichos, los modismos, la riqueza descriptiva y concisa del hablar cotidiano forman parte, no sólo del hablar de sus personajes sino también de las disquisiciones y apartes del autor, todo dentro del marco hispanoamericano sin concesiones a lo peninsular. Y para colmo ha construido el gran chiste de enhebrar en una sola entidad la famosa alienación de los europeos con el más directo significado de nuestro vocablo, el alienado-alienado, el alienado-demente, el alienado-loco de atar.

\section{Elmira College}

Esperaniza Figueroa 